\title{
Atributos físicos do solo e produtividade de milho em resposta a culturas de pré-safra
}

\author{
Eurico Lucas de Sousa Neto(1), Itamar Andrioli(2), Amauri Nelson Beutler ${ }^{(2)}$ e José Frederico Centurion ${ }^{(2)}$
}

\begin{abstract}
(1)Universidade do Estado de Mato Grosso, Departamento de Zootecnia, Caixa Postal 181, CEP 78250-000 Pontes e Lacerda, MT. E-mail: euricolucas@yahoo.com.br (2)Universidade Estadual Paulista, Faculdade de Ciências Agrárias e Veterinárias, Departamento de Solos e Adubos, Via de Acesso Prof. Paulo Donato Castellane, s/no, CEP 14884-900 Jaboticabal, SP. E-mail: itamar@fcav.unesp.br, amaurib@yahoo.com.br, jfcentur@fcav.unesp.br
\end{abstract}

Resumo - O objetivo deste trabalho foi avaliar os atributos físicos de um Latossolo Vermelho distrófico argiloso e a produtividade de milho em sistemas de manejo que incluem plantas de cobertura cultivadas em pré-safra (setembro a novembro). Foram utilizadas, durante quatro anos, as seguintes plantas de cobertura: crotalária (Crotalaria juncea); milheto (Pennisetum americanum sin. tiphoydes); lab-lab (Dolichus lablab) em sistema de semeadura direta; e pousio cultivado em sistema de preparo convencional, antecedendo o cultivo de milho. $\mathrm{O}$ delineamento experimental foi de blocos ao acaso com parcelas subdivididas e quatro repetições. Amostras de solo indeformadas foram coletadas para determinações físicas e avaliou-se a produtividade de milho em área de $22,5 \mathrm{~m}^{2}$. As plantas de cobertura no sistema de semeadura direta promoveram maior estabilidade de agregados e maior densidade do solo na camada superficial, sem alteração do conteúdo de água disponível às plantas. A utilização de lab-lab, em pré-safra, promoveu a menor produtividade de milho. A utilização de plantas de cobertura em pré-safra no sistema de semeadura direta de milho é viável no Estado de São Paulo.

Termos para indexação: Zea mays, adubação verde, cultivo seqüencial, estrutura do solo.

\section{Soil physical attributes and corn yield as a response to cover crops prior to corn}

\begin{abstract}
The objective of this work was to evaluate soil physical attributes and corn productivity of a Typic Hapludox in system including cover crops before corn. During four years the following cover crop species were used: sunn hemp (Crotalaria juncea); millet (Pennisetum americanum sin. tiphoydes); lab-lab (Dolichus lablab) in no-tillage system. An additional treatment was used with a tillage system composed of a disk plow and two harrowing. The experiment was set up in randomized block with split-plot design, with four repetitions. Undisturbed soil samples were collected for physical determinations and corn yield was evaluated in $22.5 \mathrm{~m}^{2}$ areas. The cover crop treatments in no-tillage promoted bigger aggregate stability and bulk density in the superficial layer, but did not affect the available water to the plants. The lab-lab cultivated prior to corn promoted smaller corn yield. The utilization of cover crop before main cash crop in no-tillage system improve soil quality in São Paulo State, Brazil.
\end{abstract}

Index terms: Zea mays, green manure, sequential cropping, soil structure.

\section{Introdução}

As regiões norte e nordeste do Estado de São Paulo, bem como a Região do Cerrado que abrange outros estados, apresentam inverno seco, o que compromete o cultivo de plantas de cobertura com finalidade de produção de fitomassa e melhoria das propriedades do solo, da forma que tem sido realizado com sucesso no Sul do País.

Segundo Andrioli (2004) e Suzuki \& Alves (2006), uma das alternativas é o plantio de espécies de cobertura no início da primavera, antes da cultura principal, no início do período das chuvas. Além da produção de fitomassa, que viabiliza o sistema de semeadura direta, plantas de cobertura cultivadas em pré-safra, quando leguminosas, podem fornecer nitrogênio e aumentar a produtividade de milho, conforme constatado por Bertin et al. (2005). Entretanto, há necessidade de avaliar essa prática em regiões de clima tropical com verão quente e chuvoso e inverno seco.

Há indicações de que algumas plantas podem minimizar os efeitos negativos da degradação dos solos, por meio da melhoria na agregação e estrutura (Wohlenberg et al., 2004), devido, principalmente, à ação 
mecânica das raízes ou pela excreção de substâncias com ação cimentante e, indiretamente, pelo fornecimento de nutrientes à fauna do solo, por meio da adição de restos culturais. Porém, a interação das plantas de cobertura com as propriedades físico-hídricas do solo e a conseqüente produtividade das culturas está relacionada às características intrínsecas de cada espécie, ao manejo dos resíduos culturais e às condições edafoclimáticas de cada região. Segundo Calegari et al. (1992), o uso de plantas de cobertura do solo com os sistemas de produção específicos de cada região deve ser avaliado, a fim de viabilizar o sistema de semeadura direta.

Em relação às propriedades físicas, as plantas de cobertura têm papel na melhoria da estrutura do solo, a qual, segundo Tormena et al. (1998), exerce grande influência na movimentação e infiltração de água, transferência de calor e aeração.

Wohlenberg et al. (2004), trabalhando em um Latossolo argiloso, no Triângulo Mineiro, obtiveram maior agregação do solo com a utilização de gramíneas perenes. Por sua vez, Haynes \& Beare (1997) verificaram, nos primeiros anos da implantação de sucessões de culturas, maior estabilidade de agregados com cultivo de leguminosas, devido à maior produção de biomassa e comprimento de hifas de fungos.

A melhor agregação do solo reflete na densidade e porosidade do solo (Kay \& Angers, 1999), e na retenção de água (Silva et al., 2005). Rojas \& Van Lier (1999), trabalhando com um Argissolo Amarelo observaram, na camada de 0,00-0,20 m, uma maior retenção de água, creditada a maior volume de microporos nessa camada. Por sua vez, Silva et al. (1986) obtiveram maior retenção de água em solos compactados artificialmente, condizente com aumento da densidade do solo e da microporosidade.

A adoção do sistema de semeadura direta é indicada como uma das alternativas para o surgimento de sistemas agrícolas sustentáveis, embasado nos princípios de menor revolvimento do solo e no aporte contínuo de material orgânico.

O objetivo deste trabalho foi avaliar os atributos físicos de um Latossolo Vermelho distrófico argiloso e a produtividade de milho em sistemas que incluem plantas de cobertura de solo antes (setembro a novembro) da cultura do milho.

\section{Material e Métodos}

O trabalho foi realizado em Jaboticabal, SP $\left(21^{\circ} 15^{\prime} \mathrm{S}\right.$ e $48^{\circ} 18^{\prime} \mathrm{W} ; 595 \mathrm{~m}$ de altitude). O clima é do tipo Cwa, segundo a classificação de Köppen, com temperaturas moderadas (média de $22,4^{\circ} \mathrm{C}$ ), verão quente e chuvoso e precipitação média anual de $1.285 \mathrm{~mm}$. O solo do local é um Latossolo Vermelho distrófico, típico, textura argilosa, cuja composição granulométrica na camada de

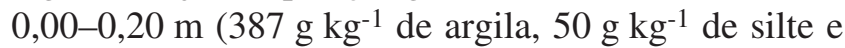
$563 \mathrm{~g} \mathrm{~kg}^{-1}$ de areia) foi determinada por meio da dispersão com $\mathrm{NaOH} 0,1 \mathrm{~mol} \mathrm{~L}^{-1}$ sob agitação lenta, durante 16 horas (50 rpm). O conteúdo de argila foi obtido pelo método da pipeta.

O delineamento experimental foi de blocos casualizados, com parcelas subdivididas (manejo $\mathrm{x}$ camada), e quatro repetições (parcelas de $200 \mathrm{~m}^{2}$ ). A área experimental foi cultivada desde 1995, com plantas de cobertura em pré-safra (setembro a novembro) e na safra com milho (1995/1997), soja (1998/ 2000) e milho (2001/2004), nos sistemas de manejo descritos na Tabela 1. De 2001 até 2004, utilizaram-se, anualmente, as seguintes espécies de cobertura em présafra ao milho (Zea mays (L.) Merril): crotalária (Crotalaria juncea) (SDC); milheto (Pennisetum americanum sin. tiphoydes) (SDM); lab-lab (Dolichus lablab), em sistema de semeadura direta (SDL); pousio e preparo convencional após uma gradagem aradora e duas niveladoras (PC).

Tabela 1. Histórico de utilização da área experimental.

\begin{tabular}{cccccccc}
\hline Sistema de manejo & \multicolumn{7}{c}{ Ano agrícola } \\
\cline { 2 - 7 } & $1995 / 1996$ & $1996 / 1997$ & $1997 / 1998$ & $1998 / 1999$ & $1999 / 2000$ & $2000 / 2001$ & $2001 / 2004$ \\
\hline SDC & Crotalária & Guandu & Crotalária & Crotalária & Milho & Nabo & Crotalária \\
SDM & Pousio & Milho & Milheto & Pousio & Guandu & Nabo & Milheto \\
SDL & Milheto & Pousio & Milheto & Milheto & Sorgo & Milheto & Lab-lab \\
PC & Pousio & Pousio & Pousio & Pousio & Pousio & Pousio & Pousio \\
\hline
\end{tabular}

${ }^{(1)}$ SDC: semeadura direta em crotalária; SDM: semeadura direta em milheto; SDL: semeadura direta em lab-lab; PC: semeadura convencional em pousio. 
A semeadura das plantas de cobertura foi realizada com semeadora de plantio direto provida de sulcador, na primeira quinzena de setembro, no espaçamento de $0,45 \mathrm{~m}$ entre linhas e 50, 40 e $30 \mathrm{~kg} \mathrm{ha}^{-1}$ de sementes de crotalária, milheto e lab-lab, respectivamente. Em dezembro, foram dessecadas mediante a aplicação de herbicida glifosate (2,4 $\mathrm{kg} \mathrm{ha}^{-1}$ de i.a.). Em seguida, foi realizada a semeadura de milho (cultivar Agromen 3150) no espaçamento de $0,90 \mathrm{~m}$ entre linhas e cinco sementes por metro. A adubação, na semeadura, foi de $400 \mathrm{~kg} \mathrm{ha}^{-1}$ da fórmula N-P-K (4-20-20) e, em cobertura, $120 \mathrm{~kg} \mathrm{ha}^{-1}$ de $\mathrm{N}$, na forma de uréia, 35 dias após a emergência das plantas.

Em março de 2005, foram coletadas amostras de solo, nas entrelinhas do milho, nas camadas de $0,00-0,05 \mathrm{me}$ 0,05-0,10 m, a fim de determinar o teor de matéria orgânica (MO) (Raij et al., 2001), e a estabilidade de agregados em água (Kemper \& Chepil, 1965).

Agregados com diâmetro entre 4,00 e 7,93 $\mathrm{mm}$ foram obtidos mediante peneiramento de material indeformado, conforme recomendações de Kemper \& Chepil (1965). A estabilidade de agregados foi determinada pelo peneiramento em água, após pré-umidecimento lento dos agregados por capilaridade (média de três repetições). $\mathrm{O}$ diâmetro médio geométrico (DMG) e o diâmetro médio ponderado (DMP) foram calculados segundo Kemper \& Chepil (1965).

Foram também coletadas amostras com estrutura preservada, com anéis volumétricos de $0,075 \mathrm{~m}$ de altura e $0,048 \mathrm{~m}$ de diâmetro $\left(0,14 \times 10^{-3} \mathrm{~m}^{3}\right)$, nas camadas de $0,000-0,075 \mathrm{~m} ; 0,075-0,150 \mathrm{~m}$ e $0,150-0,225 \mathrm{~m}$, para determinação da densidade do solo e da porosidade. A densidade do solo foi determinada pelo método do anel volumétrico e a porosidade, utilizando o método descrito por Richards (1965), empregando-se a tensão de 0,006 MPa em câmaras de Richards para separar os poros com diâmetros maiores (macroporos) e menores (microporos) que 0,05 mm. Além disso, nas mesmas amostras, determinou-se a retenção de água no solo na tensão de 1,5 MPa para determinação da água disponível, correspondente ao conteúdo de água retida na tensão de 0,03 MPa menos o conteúdo na tensão de 1,5 MPa. A produtividade de grãos de milho foi determinada, na safra 2004/2005, em uma área de $22,5 \mathrm{~m}^{2}$. A umidade dos grãos foi corrigida para $0,13 \mathrm{~kg} \mathrm{~kg}^{-1}$.

Os resultados foram submetidos à análise de variância pelo teste $\mathrm{F}$, e quando significativas, as médias foram comparadas pelo teste de Tukey, a 5\% de probabilidade.

\section{Resultados e Discussão}

Os sistemas de manejo não alteraram o teor de MO em ambas as camadas (Tabela 2). Porém, os teores de MO na camada de $0,00-0,05 \mathrm{~m}$ foram superiores aos da camada de $0,05-0,10 \mathrm{~m}$, nos sistemas de semeadura direta com utilização de plantas de cobertura. Isso se deve à adição de materiais orgânicos pelas plantas de cobertura e aos resíduos remanescentes da cultura do milho, na superfície do solo, e à natureza superficial das raízes da maioria dos vegetais (Sanchez, 1981).

Além disso, menor revolvimento do solo no sistema de semeadura direta reduz o contato do solo com os materiais vegetais e diminui a velocidade de decomposição, comparado ao sistema convencional, no qual ocorre revolvimento do solo, fragmentação, incorporação e exposição dos restos vegetais à ação mais intensa dos microrganismos, que atuam na sua decomposição. Porém, as três plantas de cobertura não diferiram em relação ao teor de MO no solo, apesar de ter sido verificada produção de matéria seca superior na SDM e SDC em relação ao SDL por Bertin et al. (2005) e Suzuki \& Alves (2006). Esse fato pode ser creditado à rápida decomposição dos restos vegetais nas condições de clima quente e chuvoso, conforme verificado por Pelá (2002), diminuindo, assim, os efeitos diferenciais das plantas no aumento da $\mathrm{MO}$ do solo.

Além disso, Oades (1984) menciona que, em condições de menor revolvimento do solo, a dinâmica da matéria orgânica é alterada, interferindo não apenas nos ciclos de transformação dos nutrientes, mas também na estruturação do solo. Essa condição é decorrente da ação da fauna do solo na fragmentação, decomposição da MO e na formação de galerias que, por sua vez, favorecem trocas gasosas mais intensas e contribuem para melhorar a agregação do solo (Castro Filho et al., 1998). Todavia, em sistemas de menor revolvimento do solo, os agregados não são fragmentados durante as operações de preparo do solo (Beutler et al., 2001).

A estabilidade de agregados, avaliada pelos índices DMG e DMP, foi superior nos sistemas de semeadura direta com utilização de plantas de cobertura comparado ao sistema de preparo convencional, na camada de $0,00-0,05 \mathrm{~m}$, não diferindo na camada de $0,05-0,10 \mathrm{~m}$. Em ambos os índices, exceto no sistema de preparo convencional, os maiores valores foram encontrados na camada superficial (Tabela 2). Segundo Brady \& Weill (1999), a formação e estabilização de agregados tem 
como principais responsáveis a atividade microbiana e as hifas de fungos. Os macroagregados se formam pela ação física, unindo os microagregados e as partículas de solo, e pelas exsudações de polissacarídeos e de outros compostos orgânicos que formam uma rede que se liga e agrupa partículas individuais de solo com pequenos microagregados.

As espécies de cobertura apresentaram efeito semelhante na estabilidade de agregados, contrariando estudos desenvolvidos no Sul do Brasil, que apontam as gramíneas como mais eficientes em relação à agregação (Reinert et al., 1984; Castro Filho et al., 1998; Wendling et al., 2005). Convém ressaltar que, embora as espécies de cobertura não tenham apresentado diferença significativa, proporcionaram aumento na estabilidade de agregados, o que pode ser creditado ao efeito acumulado das espécies crotalária, milheto e lab-lab (quatro anos), conforme avaliado.

Nos sistemas de semeadura direta, o DMG e DMP foram aproximadamente duas vezes maiores, comparados ao preparo convencional, corroborando Beutler et al. (2001), que verificaram DMG 1,9 a 2,8 vezes superior no sistema de semeadura direta. No Sul do Brasil, Reinert et al. (1984) e Tormena et al. (2002), ambos em solos argilosos, obtiveram DMG superiores 2,2 e 1,9 vez no sistema de semeadura direta, comparado ao preparo convencional, após quatro e sete anos, respectivamente.

Tabela 2. Teor médio de matéria orgânica no solo, diâmetro médio geométrico, diâmetro médio ponderado, densidade do solo, porosidade total, macroporosidade, microporosidade, água disponível e produtividade média, nos sistemas de manejo e camadas ${ }^{(1)}$.

\begin{tabular}{|c|c|c|c|c|}
\hline Camada (m) & SDC & SDM & SDL & $\mathrm{PC}$ \\
\hline & \multicolumn{4}{|c|}{ Matéria orgânica $\left(\mathrm{g} \mathrm{dm}^{-3}\right)$} \\
\hline $0,00-0,05$ & $22,2 \mathrm{Aa}$ & $22,4 \mathrm{Aa}$ & $22,0 \mathrm{Aa}$ & $18,6 \mathrm{Aa}$ \\
\hline \multirow[t]{2}{*}{$0,05-0,10$} & $17,2 \mathrm{Ab}$ & $17,2 \mathrm{Ab}$ & $17,3 \mathrm{Ab}$ & $17,9 \mathrm{Aa}$ \\
\hline & \multicolumn{4}{|c|}{ Diâmetro médio geométrico (mm) } \\
\hline $0,00-0,05$ & $2,70 \mathrm{Aa}$ & $2,73 \mathrm{Aa}$ & $2,81 \mathrm{Aa}$ & $0,96 \mathrm{Ba}$ \\
\hline \multirow[t]{2}{*}{$\underline{0,05-0,10}$} & $1,44 \mathrm{Ab}$ & $1,45 \mathrm{Ab}$ & $1,75 \mathrm{Ab}$ & $1,45 \mathrm{Aa}$ \\
\hline & \multicolumn{4}{|c|}{ Diâmetro médio ponderado (mm) } \\
\hline $0,00-0,05$ & 3,82Aa & 3,89Aa & $3,97 \mathrm{Aa}$ & $2,15 \mathrm{Ba}$ \\
\hline \multirow[t]{2}{*}{$0,05-0,10$} & $2,76 \mathrm{Ab}$ & $2,78 \mathrm{Ab}$ & $2,55 \mathrm{Ab}$ & $2,55 \mathrm{Aa}$ \\
\hline & \multicolumn{4}{|c|}{ Densidade do solo $\left(\mathrm{Mg} \mathrm{m}^{-3}\right)$} \\
\hline $0,000-0,075$ & $1,42 \mathrm{Ab}$ & $1,41 \mathrm{Ab}$ & $1,40 \mathrm{Ab}$ & $1,33 \mathrm{Bb}$ \\
\hline $0,075-0,150$ & $1,45 \mathrm{Aa}$ & $1,47 \mathrm{Aa}$ & $1,50 \mathrm{Aa}$ & $1,44 \mathrm{Aa}$ \\
\hline \multirow[t]{2}{*}{$0,150-0,225$} & $1,45 \mathrm{Aa}$ & $1,49 \mathrm{Aa}$ & $1,52 \mathrm{Aa}$ & $1,43 \mathrm{Aa}$ \\
\hline & \multicolumn{4}{|c|}{ Porosidade total $\left(\mathrm{m}^{3} \mathrm{~m}^{-3}\right)$} \\
\hline $0,000-0,075$ & $0,47 \mathrm{Aa}$ & $0,47 \mathrm{Aa}$ & $0,46 \mathrm{Aa}$ & 0,49Aa \\
\hline $0,075-0,150$ & $0,45 \mathrm{Aa}$ & $0,43 \mathrm{Aa}$ & $0,46 \mathrm{Aa}$ & $0,45 \mathrm{Aa}$ \\
\hline \multirow[t]{2}{*}{$\underline{0,150-0,225}$} & $0,42 \mathrm{Aa}$ & $0,43 \mathrm{Aa}$ & $0,42 \mathrm{Aa}$ & $0,40 \mathrm{Ba}$ \\
\hline & \multicolumn{4}{|c|}{ Macroporosidade $\left(\mathrm{m}^{3} \mathrm{~m}^{-3}\right)$} \\
\hline $0,000-0,075$ & $0,25 \mathrm{Aa}$ & $0,27 \mathrm{Aa}$ & $0,26 \mathrm{Aa}$ & $0,29 \mathrm{Aa}$ \\
\hline $0,075-0,150$ & $0,23 \mathrm{Aab}$ & $0,22 \mathrm{Bb}$ & $0,24 \mathrm{Aab}$ & $0,24 \mathrm{Ab}$ \\
\hline \multirow[t]{2}{*}{$0,150-0,225$} & $0,20 \mathrm{Ab}$ & $0,21 \mathrm{Ab}$ & $0,21 \mathrm{Ab}$ & $0,19 \mathrm{Ab}$ \\
\hline & \multicolumn{4}{|c|}{ Microporosidade $\left(\mathrm{m}^{3} \mathrm{~m}^{-3}\right)$} \\
\hline $0,000-0,075$ & $0,22 \mathrm{Aa}$ & $0,20 \mathrm{Aa}$ & $0,20 \mathrm{Aa}$ & $0,20 \mathrm{Aa}$ \\
\hline $0,075-0,150$ & $0,22 \mathrm{Aa}$ & $0,21 \mathrm{Aa}$ & $0,22 \mathrm{Aa}$ & $0,21 \mathrm{Aa}$ \\
\hline \multirow[t]{2}{*}{$0,150-0,225$} & $0,22 \mathrm{Aa}$ & $0,22 \mathrm{Aa}$ & $0,21 \mathrm{Aa}$ & $0,21 \mathrm{Aa}$ \\
\hline & \multicolumn{4}{|c|}{ Água disponível $\left(\mathrm{m}^{3} \mathrm{~m}^{-3}\right)$} \\
\hline $0,000-0,075$ & $0,12 \mathrm{Aa}$ & $0,12 \mathrm{Aa}$ & $0,11 \mathrm{Aa}$ & $0,11 \mathrm{Aa}$ \\
\hline $0,075-0,150$ & $0,12 \mathrm{Aa}$ & $0,11 \mathrm{Aa}$ & $0,12 \mathrm{Aa}$ & $0,12 \mathrm{Aa}$ \\
\hline \multirow[t]{3}{*}{$0,150-0,225$} & $0,10 \mathrm{Aa}$ & $0,11 \mathrm{Aa}$ & $0,11 \mathrm{Aa}$ & $0,12 \mathrm{Aa}$ \\
\hline & \multicolumn{4}{|c|}{ Produtividade média $\left(\mathrm{kg} \mathrm{ha}^{-1}\right)$} \\
\hline & $5.680 \mathrm{~A}$ & $5.480 \mathrm{~A}$ & $4.170 \mathrm{~B}$ & $5.320 \mathrm{~A}$ \\
\hline
\end{tabular}

${ }^{(1)}$ Médias seguidas da mesma letra, maiúscula na linha e minúscula na coluna, em cada variável, não diferem entre si pelo teste de Tukey, a 5\% de probabilidade; SDC: semeadura direta em crotalária; SDM: semeadura direta em milheto; SDL: semeadura direta em lab-lab; PC: semeadura convencional em pousio. 
A densidade do solo, na camada de $0,000-0,075 \mathrm{~m}$, foi maior nos sistemas de semeadura direta comparado ao PC (Tabela 2), corroborando estudos desenvolvidos por Secco et al. (2005). Tal situação se deve ao revolvimento do solo apenas na linha de semeadura, nos sistemas de semeadura direta, comparado ao preparo convencional, no qual o solo foi revolvido até a profundidade de $0,20 \mathrm{~m}$. Porém, em todos os sistemas, a densidade do solo foi menor na camada de 0,000-0,075 m, se comparado às camadas de $0,075-0,150 \mathrm{e} 0,150-0,225 \mathrm{~m}$. Essa condição demonstra efeito benéfico das plantas de cobertura no sistema de semeadura direta, na camada superficial do solo. Outro fator que também contribui com valores menores de densidade do solo na camada superficial são os sucessivos ciclos de umidificação e secagem, mais atuantes na camada superficial, que promovem a formação de agregados maiores e, conseqüentemente, menor densidade do solo (Wendling et al., 2005).

A densidade do solo variou de 1,33 a 1,52 $\mathrm{Mg} \mathrm{m}^{-3}$, e foi inferior ao valor de $1,55 \mathrm{Mg} \mathrm{m}^{-3}$, considerado limitante para culturas anuais em solos com 200 a $550 \mathrm{~g} \mathrm{~kg}^{-1} \mathrm{de}$ argila, no Sul do Brasil (Reichert et al., 2003), e próximo de 1,48 $\mathrm{Mg} \mathrm{m}^{-3}$, em que Beutler et al. (2005) obtiveram a máxima produtividade de soja em solo e clima semelhante. Assim, a densidade do solo não foi fator limitante da produtividade nos sistemas de manejo, indicando que o sistema de semeadura direta com utilização de plantas de cobertura em pré-safra não compacta o solo em níveis prejudiciais à produtividade de culturas anuais.

Valores de densidade do solo não-limitantes refletiram em valores de macroporosidade superiores a $0,10 \mathrm{~m}^{3} \mathrm{~m}^{-3}$, abaixo do qual o crescimento de plantas é restringido (Grable \& Siemer, 1968). Segundo Silva et al. (2004), esse é o valor de porosidade mínima para trocas líquidas e gasosas entre o ambiente externo e o solo, e a partir do qual o crescimento de plantas de milho é fortemente reduzido. Neste contexto, valores de macroporosidade do solo acima de $0,19 \mathrm{~m}^{3} \mathrm{~m}^{-3}$, em todos os sistemas de manejo e camadas, confirmam que a compactação do solo não foi limitante à produtividade do milho.

$\mathrm{O}$ volume de macroporos diminuiu em profundidade, como também ocorreu inversamente aumento da densidade do solo, ou seja, o aumento da densidade do solo corresponde à menor aeração do solo. Porém, não ocorreu alteração da microporosidade do solo, em virtude de os microporos serem mais resistentes à deformação e pouco alterados pela compactação em Latossolos. Silva \& Kay (1997) afirmam ser a microporosidade fortemente influenciada pela textura e teor de carbono orgânico e pouco influenciada pela densidade do solo.

A água disponível, considerada como o conteúdo de água entre as tensões de 0,03 e 1,5 MPa, variou de 0,10 a $0,12 \mathrm{~m}^{3} \mathrm{~m}^{-3}$ e não diferiu entre os sistemas de manejo e profundidades (Tabela 2). A produtividade de milho foi semelhante entre os sistemas de semeadura direta com utilização de plantas de cobertura e o sistema convencional depois do pousio, exceto na utilização da espécie lab-lab (SDL), que proporcionou a menor produtividade (Tabela 2). Bertin et al. (2005), nas mesmas condições experimentais, embora não tenham encontrado diferença significativa para a produção de milho, não recomendam o lab-lab como espécie de cobertura para a região nordeste do Estado de São Paulo.

Andrioli (2004), também sob as mesmas condições experimentais, obteve menor quantidade de fitomassa na utilização de lab-lab como espécie de cobertura, o que proporcionou menor quantidade de nitrogênio acumulado na parte aérea de milho. Segundo Stute \& Posner (1995), embora as fabáceas, como o lab-lab, tenham capacidade de fixação simbiótica de $\mathrm{N}$ atmosférico, para que haja máximo aproveitamento pela cultura subseqüente, há necessidade de um sincronismo entre a liberação dos nutrientes pelos resíduos culturais e a demanda do elemento pela cultura.

Este trabalho permite inferir que maior estabilidade de agregados e valores superiores de densidade do solo no sistema de semeadura direta, na camada superficial, comparado ao sistema convencional, não causaram alterações na produtividade, confirmando a viabilidade do sistema de semeadura direta, quando são utilizadas plantas de cobertura em pré-safra ao milho, na região nordeste do Estado de São Paulo.

\section{Conclusões}

1. Plantas de cobertura, no sistema de semeadura direta, aumentam a estabilidade de agregados, alterando o conteúdo de água disponível às plantas.

2. Nas condições estudadas, a utilização de lablab em pré-safra promove a menor produtividade de milho.

\section{Referências}

ANDRIOLI, I. Plantas de cobertura em pré-safra à cultura do milho em plantio direto, na região de Jaboticabal-SP. 2004. 78p. Tese (Livre Docência) - Universidade Estadual Paulista, Jaboticabal. 
BERTIN, E.G.; ANDRIOLI, I.; CENTURION, J.F. Plantas de cobertura em pré-safra ao milho em plantio direto. Acta Scientiarum, v.27, p.379-386, 2005.

BEUTLER, A.N.; CENTURION, J.F.; SILVA, A.P. Soil resistance to penetration and least limiting water range for soybean yield in a haplustox from Brazil. Brazilian Archives of Biology and Technology, v.48, p.863-871, 2005.

BEUTLER, A.N.; SILVA, M.L.N.; CURI, N.; FERREIRA, M.M.; PEREIRA FILHO, I.A.; CRUZ, J.C. Agregação de Latossolo Vermelho distrófico típico relacionada com o manejo na região dos cerrados no Estado de Minas Gerais. Revista Brasileira de Ciência do Solo, v.25, p.129-136, 2001.

BRADY, N.C.; WEIL, R.R. The nature and properties of soils. 12.ed. New Jersey: Prentice Hall, 1999. 960p.

CALEGARI, A.; MONDARDO, A.; BULISANI, E.A.; WILDNER, L. do P.; COSTA, M.B.B.; ALCANTARA, P.B.; MIYAZAKA, S.; AMADO, T.J.C. Adubação verde no sul do Brasil. Rio de Janeiro: AS-PTA, 1992. 346p.

CASTRO FILHO, C.; MUZILLI, O.; PODANOSCHI, A.L. Estabilidade dos agregados e sua relação com o teor de carbono orgânico num Latossolo Roxo distrófico, em função de sistemas de plantio, rotações de culturas e métodos de preparo das amostras. Revista Brasileira de Ciência do Solo, v.22, p.527-538, 1998.

GRABLE, A.R.; SIEMER, E.G. Effects of bulk density, aggregate size, and soil water suction on oxygen diffusion, redox potentials and elongation of corn roots. Soil Science Society of America Journal, v.32, p.180-186, 1968.

HAYNES, R.J.; BEARE, M.H. Influence of six crop species on aggregate stability and some labile organic matter fractions. Soil Biology and Biochemistry, v.29, p.1647-1653, 1997.

KAY, B.D.; ANGERS, D.A. Soil structure. In: SUMNER, M.E. (Ed.). Handbook of soil science. Boca Raton: CRC Press, 1999. p.229-276.

KEMPER, W.D.; CHEPIL, W.S. Size distribution of aggregates: In: BLAKE, C.A.; EVANS, D.D.; WHITE, J.L.; ENSMINGER, L.E.; CLARK, F.E. (Ed.). Methods of soil analysis: physical and mineralogical properties, including statistics of measurement and sampling. Madison: American Society of Agromony, 1965. p.499510.

OADES, J.M. Soil organic matter and structural stability: mechanisms and implications for management. Plant and Soil, v.76, p.319-337, 1984.

PELÁ, A. Uso de plantas de cobertura em pré-safra e seus efeitos nas propriedades físicas do solo e na cultura do milho em plantio direto na região de Jaboticabal-SP. 2002. 53p. Dissertação (Mestrado) - Universidade Estadual Paulista, Jaboticabal.

RAIJ, B. van; QUAGGIO, J.A.; CANTARELLA, H. Análise química para avaliação da fertilidade de solos tropicais. Campinas: Instituto Agronômico, 2001. 285p.

REICHERT, J.M.; REINERT, D.J.; BRAIDA, J.A. Qualidade dos solos e sustentabilidade de sistemas agrícolas. Ciência e Ambiente, v.27, p.29-48, 2003.
REINERT, D.J.; MUTTI, L.S.M.; ZAGO, A.; AZOLIN, M.A.D.; HOFFMANN, C.L. Efeito de diferentes métodos de preparo de solo sobre a estabilidade de agregados em solo Podzólico VermelhoAmarelo. Ciência Rural, v.19, p.19-25, 1984.

RICHARDS, L.A. Physical conditions of water in soil. In: BLAKE, C.A. (Ed.). Methods of soil analysis. Madison: American Society of Agronomy; American Society for Testing and Materials, 1965. p.128-152.

ROJAS, C.A.L.; VAN LIER, Q.J. Alterações físicas e hídricas de um Podzólico em função de sistemas de preparo. Pesquisa Agropecuária Gaúcha, v.5, p.105-115, 1999.

SANCHEZ, P.A. Suelos del trópicos: características y manejo. San José: IICA, 1981. 634p.

SECCO, D.; DA ROS, C.O.; SECO, J.K.; FIORIN, J.E. Atributos físicos e produtividade de culturas em um Latossolo Vermelho argiloso sob diferentes sistemas de manejo. Revista Brasileira de Ciência do Solo, v.29, p.407-414, 2005.

SILVA, A.P.; IMHOFF, S.; KAY, B. Plant response to mechanical resistance and air-filled porosity of soils under conventional and notillage system. Scientia Agricola, v.61, p.451-456, 2004.

SILVA, A.P.; KAY, B.D. Estimating the least limiting water range of soils from properties and management. Soil Science Society of America Journal, v.61, p.877-883, 1997.

SILVA, A.P.; LIBARDI, P.L.; CAMARGO, O.A. Influência da compactação nas propriedades físicas de dois Latossolos. Revista Brasileira de Ciência do Solo, v.10, p.91-95, 1986.

SILVA, M.A.S. da; MAFRA, A.L.; ALBUQUERQUE, J.A.; BAYER, C.; MIELNICZUK, J. Atributos físicos do solo relacionados ao armazenamento de água em um Argissolo Vermelho sob diferentes sistemas de preparo. Ciência Rural, v.35, p.544-552, 2005.

STUTE, J.K.; POSNER, J.L. Synchrony between legume nitrogen release and corn demand in the Upper Midwest. Agronomy Journal, v.87, p.1063-1069, 1995.

SUZUKI, L.E.A.S.; ALVES, M.C. Fitomassa de plantas de cobertura em diferentes sucessões de culturas e sistemas de cultivo. Bragantia, v.5, p.121-127, 2006.

TORMENA, C.A.; BARBOSA, M.C.; COSTA, A.C.S. da; GONÇALVES, A.C.A. Densidade, porosidade e resistência à penetração em Latossolo cultivado sob diferentes sistemas de preparo do solo. Scientia Agricola, v.59, p.795-801, 2002.

TORMENA, C.A.; ROLOFF, G.; SÁ, J.C.M. Propriedades físicas do solo sob plantio direto influenciadas por calagem, preparo inicial e tráfego. Revista Brasileira de Ciência do Solo, v.22, p.301-309, 1998.

WENDLING, B.; JUCKSCH, I.; MENDONÇA, E. de S.; NEVES, J.C.L. Carbono orgânico e estabilidade de agregados de um Latossolo Vermelho sob diferentes manejos. Pesquisa Agropecuária Brasileira, v.40, p.487-494, 2005.

WOHLENBERG, E.V.; REICHERT, J.M.; REINERT, D.J.; BLUME, E. Dinâmica da agregação de um solo franco-arenoso em cinco sistemas de culturas em rotação e em sucessão. Revista Brasileira de Ciência do Solo, v.28, p.891-900, 2004. 